\title{
La perspectiva discursiva para la investigación en ciencias sociales
}

\section{(The discursive perspective for research in social sciences)}

\author{
*Mariela Díaz Fernández \\ Universidad de Oriente, Cumaná - Venezuela \\ *Email de correspondencia: marieladiazf27@yahoo.com
}

\section{RESUMEN}

El presente trabajo busca, desde el análisis crítico del discurso, identificar cuáles son las valoraciones y creencias que atribuyen los docentes a los estudiantes que asisten a las escuelas comunes. Para ello, se interpretó, en el discurso de un grupo de docentes de primaria, sus actitudes hacia los estudiantes con discapacidad, a través de los indicadores cognitivo, afectivo y conductual. Asimismo, se reveló las estrategias discursivas usadas por los docentes, que evidencian rasgos discriminatorios asociados a creencias, emociones y acciones en torno a la discapacidad. Los datos fueron recolectados a partir de conversaciones simultaneas entre el investigador y los participantes. Con el propósito de abrir el canal de interacción de manera natural, las conversaciones se iniciaron con comentarios, preguntas y reflexiones. La reflexión de los participantes hacia los tópicos abordados, primó en el transcurso de las conversaciones. Como resultado de la investigación, se evidencio, en el discurso de los docentes, diferencias significativas en las actitudes que tienen con respecto a los educandos con discapacidad y su proceso de integración escolar. Expresiones como: iQué lástima!, iNo puede aprender!, iNunca atiende!, iNo puede!, hacen notorio los rasgos discursivos asociados a un modelo de pensamiento que valida y justifica la discriminación de las personas con discapacidad. La evidencia lingüística revela también el temor de las docentes para expresar abiertamente sus creencias, emociones y formas de accionar frente al proceso de integración educativa de las personas con discapacidad.

Palabras clave: discurso; análisis crítico del discurso; estrategias discursivas; discriminación; escuela primaria; discapacidades. 


\begin{abstract}
This work seeks to identify, from the critical discourse analysis, what the appraisals and beliefs that teachers attribute to students who attend public schools are. For this purpose, a group of primary school teachers' attitudes towards students with disabilities was interpreted from their discourse considering cognitive, affective and behavioral indicators. Similarly, the discursive strategies used by teachers, which demonstrate traits associated with discriminatory beliefs, emotions, and actions on disability were revealed. Data were collected from simultaneous conversations between the researcher and participants. In order to open the channel of communication naturally, the conversations began with comments, questions, and reflections. The reflection of the participants about the topics addressed, prevailed during the interlocution. As a result of the investigation, the discourse of teachers showed significant differences in the attitudes they have regarding learners with disabilities and their school integration process. Expressions like What a pity! He is not able to learn! He never pays attention! He can't!, make noticeable the discursive features associated with a pattern of thought that validates and justifies discrimination against persons with disabilities. Linguistic evidence also reveals the teachers' fear to openly express their beliefs, emotions, and actions against the process of educational integration of people with disabilities.
\end{abstract}

Keywords: discourse; critical discourse analysis; discursive strategies; discrimination; elementary school; disabilities. 


\section{INTRODUCCIÓN}

Desde hace un poco más de una década comencé a incursionar en los estudios del discurso, particularmente en el análisis crítico del discurso (en adelante ACD). Al principio, esa tarea representaba para mí una aventura que me generaba un poco de temor a lo desconocido. Sin embargo, resultaba sorprendente ir descubriendo la extraordinaria fuerza del lenguaje y el accionar humano para provocar efectos sociales desde la discursividad, sobre todo porque me permitía observar el modo en que el poder político y social, el dominio y la desigualdad son practicados, reproducidos $\mathrm{y}$, ocasionalmente, combatidos a través del lenguaje. Además, la posibilidad de contrastar realidades me otorgaba la posibilidad de reflexionar sobre cómo las diversas prácticas discursivas marcan la existencia individual y colectiva.

Cautivada por la complejidad de los estudios del discurso y seducida por la profundidad de su contenido, inicié un camino investigativo que me ha dado la oportunidad valiosa de construir espacios para la discusión y la reflexión desde una concepción interactiva e intersubjetiva del lenguaje, al concederle un valor esencial a las relaciones interpersonales y a las particularidades contextuales y culturales en los procesos de co construcción de los diferentes discursos sociales.

Toda esta configuración de elementos subjetivos e intersubjetivos que se entrecruzan al investigar sobre el uso del lenguaje por parte de grupos humanos, me obligó a caminar en puntillas para ir sorteando obstáculos, en este caso representados por mis prefiguraciones e interpretaciones de las realidades estudiadas. Digo esto porque la comprensión de las prácticas discursivas de los otros está marcada por nuestros esquemas socioculturales y ello puede convertirse en un riesgo metodológico de alto calibre.

A la luz de toda mi experiencia, que como lingüista iba alimentando con la revisión documental y los intercambios en actividades académicas, comprendí con mayor firmeza argumentativa que para ser un analista del discurso es necesario tener en cuenta que lo gramatical en sí mismo no puede ser la única vía para profundizar en la comprensión de los textos y sus contextos; que la interdisciplinariedad metódica es la clave para lograr entender cómo funcionan las prácticas discursivas, cómo es la dinámica de la sociedad y de sus problemas, cómo el lenguaje es acción que instala dispositivos de formación para moldear la mente de las personas.

Una vez que se tiene claridad teórica sobre lo que significa analizar discursos podemos reflexionar con conciencia crítica sobre el lenguaje y su valor, no sólo expresivo sino también ideológico. En virtud de ello, mis reflexiones me llevaron a buscar apoyo en otros que, como yo, se han formulado cuestionamientos similares a los míos para afirmar que el ACD exige la puesta en escena de lo multidisciplinario (en materia de teorías y métodos), pues es la inmejorable ruta preclara para comprender el significado, los sentidos y la finalidad de lo humano, con toda su riqueza subjetiva e intersubjetiva. Ello nos mueve a la búsqueda de conocimientos más integrales, desde perspectivas epistemológicas interdisciplinarias, con capacidad de profundizar en lo subjetivo y en lo trascendente.

En la actualidad, puedo afirmar que para ser un investigador de lo social, y allí entramos los analistas del discurso, es urgente y necesario liberar la conciencia epistémica simplista, restringida a comprobar teorías y/o centrarse solo en datos. Si no lo hacemos, no podemos trascender en la aventura de aproximarnos a un objeto de estudio desde la convivencia textual, discursiva. Solo así se podrá descubrir lo que subyace en el lenguaje, lo que revela creencias, representaciones del mundo, prejuicios, valoraciones diversas. Y solo así podremos generar las transformaciones sociales que esas categorías, inherentes a lo humano, demandan.

De este modo, y centrándome en el ACD como enfoque analítico dirigido especialmente a temas o problemas sociales y también académicos, la investigación científica se convierte en funcional toda vez que, dentro de un marco sociocultural amplio, examina los mecanismos sociopolíticos, históricos, culturales, que sustentan la reproducción del poder, y, por lo tanto, presta especial atención al análisis de las ideologías que alimen- 
tan, reproducen o legitiman mecanismos de dominación, deslegitimación y opresión.

Este escenario de investigación me ha permitido interactuar con una perspectiva flexible, desde donde he accedido a la comprensión de lo teórico, a su aplicabilidad en el análisis, y a la asunción de una mirada crítica para buscar caminos poco explorados y establecer nuevos objetos de estudio.

En los próximos apartados presento distintas instancias textuales desde donde planteo una mirada otra para adentrarnos en la comprensión de lo social mediante una perspectiva inter y multidisciplinaria en la que la lingüisticidad y lo propiamente lingüístico nos proporcionan las claves para el análisis y la reflexión de los procesos sociales y de las posibles repercusiones de lo discursivo.

\section{ACD: LA PERSPECTIVA DEL INVESTIGADOR FRENTE AL OBJETO DE ESTUDIO}

En mis planteamientos sobre cómo abordar la realidad objeto de estudio en una investigación, la primera acción a considerar es desde cuál visión epistemológica voy a adentrarme en el fenómeno o problema que me interesa estudiar. A su vez, la delimitación y descripción del objeto de estudio me permiten ir configurando los senderos metodológicos por los cuales voy a transitar, aunque eso no es definitivo, pues en ese itinerario pueden producirse desvíos, en atención a lo que va surgiendo en el transcurso de lo investigado.

Desde mi interés por la investigación interdisciplinaria para penetrar en el lenguaje contextualizado con una mirada crítica, considero algunas premisas relevantes, que otorgan, en buena medida, legitimidad a la investigación:

- El discurso es una práctica social: esta noción se corresponde con lo que van Dijk (2000) ha planteado sobre la comunicación como evento que no puede reducirse a un mero proceso mecánico de transmisión de información, pues al hablar del plano de la discursividad, debe ser enten- dido como un serio proceso de interpretación de intenciones realizadas por los sujetos hablantes acerca del mundo en el cual comparten sus experiencias. Aquí entran en juego la visión de mundo y las intencionalidades derivadas de la situación comunicativa.

- El discurso es interacción: esto alude al hecho que los significados se originan, se transforman y se resignifican en el contexto de lo social y no en trincheras aisladas de lo contextual. De esta manera, tal como lo afirma Iñiguez (2003, p. 119), "el lenguaje es una parte de la sociedad y no algo externo a ella; es un proceso social; es un proceso condicionado socialmente, históricamente, en el mismo sentido que lo son otras partes o procesos no lingüísticos". La consideración del discurso como interacción, se fundamenta, entonces, en la imbricación del lenguaje en los procesos sociales y la asunción de estos últimos, en importante medida, como hechos lingüísticos.

- El discurso es cognición social: me refiero con esto a la relación entre el conocimiento y las representaciones del mundo, por parte de los hablantes, en atención a los contextos sociales en los que se comparte la cotidianidad. van Dijk (2003, p. 150) menciona que para comprender el poder de los discursos es indispensable partir de la cognición social, en la cual se integran conocimientos, actitudes, ideologías, creencias, normas, valores, por lo que ella involucra "procesos mentales, experiencias personales y representaciones socioculturales que tenemos como usuarios de la lengua y que sirven de "interface" entre el discurso y la sociedad"

- El discurso es historia: esta premisa define los significados y sentidos del presente como derivas de procesos evolutivos en los que los marcos socioculturales de cada época condicionan la discursividad y la ajustan y acoplan de acuerdo con el contexto donde se enmarque. 
- El discurso es acción: en este caso, considero al igual que Bolívar (2007, p. 22) que "con la palabra se construyen y transforman realidades". El discurso como hecho social se construye en actos de comunicación y estos son puestos en práctica por los hablantes no sólo para textualizar sus intencionalidades sino también para generar acciones. Tal como lo apuntaba Wittgenstein, filósofo que propuso la teoría del significado como uso (1958, p. 421): "el lenguaje es como una máquina en funcionamiento que realiza su trabajo: las actividades cotidianas de la vida. $\mathrm{Y}$ es de naturaleza social por cuanto su uso está determinado por una sociedad específica". En concordancia con Wittgenstein, Austin, también representante de la escuela de Oxford, concebía el lenguaje no sólo como un sistema de signos organizados en estructuras con significados específicos, sino como un entramado de signos que adquieren significaciones en atención a los usos que los hablantes hacen de ellos. Núñez (2007), al hacer un estudio crítico sobre los postulados de Wittgenstein y Austin, señala que, a pesar de las restricciones que puedan evidenciarse en las teorías filosóficas de estos autores, sus aportes siguen siendo relevantes para los analistas del discurso, pues han permitido reafirmar que el uso de lo lingüístico no puede desligarse de las intencionalidades o propósitos inherentes a los hablantes.

En el caso de una investigación particular, que de manera sintética les mostraré más adelante, centré mi interés en los aspectos 1,3 y 5, aunque eso no significó que los demás no fuesen considerados.

En el entramado de estas condiciones del discurso, persigo la búsqueda de conocimientos desde una perspectiva interdisciplinaria para poder sumergirme en lo subjetivo, comprender la discursividad con la fuerza que recorre lo cog- noscible, lo sensible, lo afectivo. De acuerdo con Soriano (2005), el hombre es un ser bio- psicosocio- histórico, en permanente interacción comunicativa, intrapersonal e interpersonal. Por ello es necesario el despliegue de una conciencia crítica que apunte hacia la interioridad del ser humano y de sus más genuinas potencialidades.

En este marco de ideas vinculantes concibo mi propuesta de investigación, en el contexto interdisciplinar del ACD. La misma adquiere su sentido al construirse sobre la base de una fortalecida coherencia entre la naturaleza de la realidad objeto de estudio (dimensión ontológica), las relaciones frente a lo cognoscible (dimensión epistemológica) y el proceder en la forma de construir el conocimiento (dimensión metodológica). Aunado a esto, no podemos dejar de considerar lo axiológico y lo teleológico, pues ambas esferas transversalizan el proceso investigativo en la dimensión ética del ser investigador y en la misma intencionalidad del quehacer investigativo.

Mi acercamiento ontoepistemológico al ámbito de estudio desde el ACD, precisa la consideración del término discurso como objeto de análisis. Por otra parte, al orientar mi interés hacia la manifestación de subjetividades, creencias, representaciones, en torno a un tema o problema social, examino cuidadosamente el contexto histórico social para precisar las concepciones de términos, frases, ideas, que en el devenir epocal hayan venido expresándose como un particular discurso en el encuadre de una o más sociedades.

Ahora bien, en ese proceso de construcción del objeto de estudio, el pensar en las preguntas de investigación requiere comprender que una etapa investigativa se arma en unión con el resto de las mismas. Por ejemplo, al delimitar el objeto de estudio, podemos ir pensando en observancias teóricas y metodológicas pertinentes, armonizadas con nuestros propósitos.

Al mismo tiempo, asumo mi actuación como observadora subjetiva, lo cual me "obliga" a expresar verbalmente las características de la relación que establezco con mi objeto de investigación. De esta manera, la práctica de investigar se hace más confiable y autónoma, toda vez que el investigador, desde su punto de anclaje, mani- 
fiesta con total claridad su perspectiva investigacional.

\section{EL ACD: DESPLIEGUE TEÓRICO Y ALGUNAS HERRAMIENTAS DE ANÁLISIS}

En esta sección discurriré, sin pretensiones de exhaustividad, sobre los principios teóricos cardinales del ACD y algunas de sus herramientas de análisis para el abordaje del discurso como práctica social. Mi interés central es mostrar cómo, desde el ACD como espacio de saber interdisciplinar, el lenguaje codificado en recursos lingüísticos y en estrategias discursivas de distinto nivel nos permite penetrar en los hablantes, en sus enunciaciones, para entrar en una relación dialéctica con su visión de lo social, sus valores, sus actitudes, sus propósitos. Esto implica que el discurso es un lugar desde el cual edificamos nuestras representaciones sobre hechos, ideas, interacciones sociales. Y en esa arquitectura de lo discursivo se ponen de manifiesto reflexiones importantes sobre el lenguaje como práctica social. De allí la conveniencia de que los hablantes nos situemos en la esfera de lo crítico para así poder ser conscientes de nuestro rol como ciudadanos.

Centrándome en el ACD, es importante subrayar que este enfoque, como espacio de investigación social, se legitimó a comienzos de la década de 1990, en el contexto de un evento realizado en Amsterdam en el cual intervinieron investigadores actualmente reconocidos como Teun van Dijk, Norman Fairclough, Van Leeween, Ruth Wodak (Wodak, 2003), quienes realizaron aportes relevantes para la conformación del ACD como enfoque disciplinar dentro de los estudios del discurso. Hoy en día el ACD se ha fortalecido como herramienta teórica y metodológica para investigar en las ciencias sociales y ha cobrado auge en Latinoamérica con los aportes constantes de investigadores como Bolívar (2004), Molero (2003), Berardi (2003), entre otros.

Es necesario apuntar que el ACD se prefiguró teóricamente con los aportes de distintos estudiosos del lenguaje, siendo Fairclough (1992) uno de sus protagonistas, seguido luego de otros brillantes investigadores como Van Dijk, Wodak,
Van Leeuwen, entre otros.

Fairclough centró su metódica en el estudio del discurso desde las relaciones entre el cambio sociocultural y el cambio en el discurso. Propuso un modelo teórico organizado sobre la base de tres ejes fundamentales: el discurso como práctica textual, el discurso como práctica discursiva y el discurso como práctica social.

En el primer eje, el discurso se constituye en la unidad de análisis, caracterizada por sus propiedades de cohesión y coherencia. Esta concepción alude al texto como una producción en la que los enunciados se vinculan semánticamente entre sí para conformarse en una estructura organizativa en la cual intervienen mecanismos cohesivos lexicales y gramaticales que fortalecen la coherencia textual. Pero además de estos aspectos, al ser práctica textual, el texto implica la presencia de un agente productor que, además, asume evaluaciones y actitudes sobre lo dicho, esto es modaliza sus enunciados, mediante lo cual es posible evidenciar posiciones a favor o en contra de lo que se enuncia.

En cuanto al segundo eje, el discurso como práctica discursiva, su caracterización se desprende de los principios de la teoría pragmática y de la linguística funcional, mediante los cuales el discurso ineludiblemente tiene lugar en un espacio, un tiempo y un contexto situacional específico en el que los roles sociales de los agentes y los marcos culturales son definitorios. La concepción del discurso como práctica discursiva da cuenta del binomio texto-contexto, en el sentido de que el contexto incide en el amoldamiento del discurso, pero también el discurso adjunta significados y sentidos a las acciones sociales y posibilita cambios en los contextos sociales donde se pone en acción.

En el estudio del lenguaje como práctica discursiva toman fuerza las investigaciones sobre ordenamientos en la producción y comprensión de los discursos. Cobran gran significancia aquí factores de orden sociolingüístico como los registros, el género, el contexto discursivo los cuales condicionan el uso del lenguaje para regular las dinámicas interactivas en contextos disímiles.

Sobre el tercer eje, el discurso como práctica 
social, su definición está marcada por los trabajos de la escuela francesa del análisis del discurso y también por los de la lingüística crítica. En esta visión del lenguaje en acción, la arqueología del discurso se constituye por la relación dialéctica entre estructuras y relaciones sociales.

También, en el marco de la lingüística crítica como método del ACD, investigadores como Fowler, Hodge, Kress y Trew (1979), Kress y Hodge (1979), proponen que la conformación gramatical de un texto está influencia discursivamente por los hablantes, pues las elecciones lingüísticas que hacemos atiende a la intencionalidad de reproducir significados ideológicos y de consolidar representaciones sociales. Dentro de las investigaciones desde la lingüística crítica cobran relevancia las dedicadas al análisis de tipos discursivos para observar en ellos cómo se construyen las lexicalizaciones de lo social y experiencial.

Un enfoque de amplia significancia en el contexto del ACD es la semiótica social, cuyo propósito central es el abordaje de lo multisemiótico en los textos, sobre todo lo concerniente a la vinculación discursiva entre lenguaje verbal e imágenes. Autores como Kress y Van Leeuwen (1990) se ocuparon ampliamente de esta temática. También, dentro de este enfoque se otorgó un lugar protagónico al estudio de los géneros, considerando la propuesta de Bajtín y se realizaron trabajos relevantes en torno a los géneros discursivos en el marco de lo lingüístico en relación con los estudios culturales.

Van Dijk (1994, 1997, 2003), por su parte, propone un abordaje ideológico del discurso, desde un enfoque sociocognitivo. Sus principios fundamentales atienden a tres conceptos básicos, discurso, cognición y sociedad. Este enfoque crítico permite explicar la función del lenguaje en la reproducción de prácticas ideológicas dominantes, es decir, aquellas ideologías empleadas por los grupos que controlan el poder y ejercen dominio sobre los grupos dominados en una sociedad. De esta forma, el discurso estaría al servicio de propósitos persuasivos, con el fin de lograr consenso mediante la manipulación.

Según el enfoque proclamado por van Dijk, que es el que asumo con mayor énfasis en mis investigaciones, sin descartar la presencia de otros no menos importantes, el propósito central del ACD es centrarse en problemas sociales, por lo cual esta propuesta se erige para desentrañar de qué manera los que están en el poder usan el lenguaje para manipular la mente de los grupos dominados y controlar las acciones de estos, a favor de sus intereses, ejerciendo la dominación y reproducción de la desigualdad y la injusticia social.

Para poder comprender el poder del discurso de la manipulación y del control y desigualdad, el citado autor considera necesario partir de la cognición social, que ya hemos definido en páginas anteriores. En atención a esto solamente mediante la cognición social se puede hacer una introyección de la comprensión del discurso, pues al leer un texto realizamos interpretaciones, nos apropiamos de saberes, movilizamos conocimientos, realizamos inferencias, generamos anticipaciones, entre otras estrategias de tipo cognitivo. Es decir, construimos una representación semántica del texto y tal representación es el producto de procesos cognitivos donde entran en juego la textualidad, la contextualidad y los marcos conceptuales y socioculturales del lector.

Otra clave teórica importante dentro de este enfoque sociocognitivo es la noción de ideología, concepto que se maneja de manera diferencial en el campo de lo filosófico, político, sociológico; de allí que sus sentidos apunten a múltiples valencias y se construyan siguiendo los lineamientos epistémicos de cada disciplina del conocimiento.

En el desarrollo de mis investigaciones me he centrado básicamente en lo propuesto por Van Dijk (2006, p. 175), quien asume la ideología desde un marco lingüístico y cognitivo para referirse a las creencias que representan la "gramática de las prácticas simbólicas de un grupo". En este sentido, al ser presentada como creencias de grupos sociales, evidentemente las ideologías están asociadas a la cognición y fundamentan las prácticas sociales de sus miembros, haciendo referencia a aspectos de orden social, político, cultural, entre otros.

Vistos entonces algunos enfoques particulares dentro del ACD, podemos reafirmar, median- 
te las palabras de Wodak (2003, p. 19), que la misión primaria del ACD es estudiar, estén explícitas o implícitas estratégicamente en los textos "las relaciones de dominación, discriminación, poder y control, tal como se manifiestan a través del lenguaje. En otras palabras, el ACD propone investigar de forma crítica la desigualdad social tal como viene expresada, señalada, constituida, legitimada., por los usos del lenguaje".

Resulta también valioso destacar aquí el hecho que el ACD abre las puertas a la investigación multidisciplinaria, porque concibe las relaciones entre el lenguaje y lo social no sólo como campo inscrito en teorías y enfoques analíticos del ámbito lingüístico, sino que, por el contrario, subraya el compromiso de las teorías sociales que, desde diversas miradas epistemológicas, se han propuesto indagar, con conciencia crítica, problemas concernientes a las relaciones entre el lenguaje, la cultura, las desigualdades entre las personas.

En vista de ello, en la perspectiva teórico-metodológica que, a manera de ejemplo, presentaré en el último apartado de este trabajo, destaco la importancia de la psicología social como teoría que de manera mancomunada con el ACD me permitió problematizar sobre una temática en la que se ponen de manifiesto formas de representación social que aluden a actitudes discriminatorias, particularmente en el contexto educativo. La consideración de lo histórico resultó igualmente valiosa al hacer posible que algunos significados se interpretaran a la luz de su recorrido diacrónico en distintas sociedades marcadas culturalmente por modelos de actuación. También, como parte de mis fundamentos epistemológicos, incorporo la hermenéutica como enfoque que, tal como lo afirma Gadamer (1992) explica que la comprensión se entiende como modo de ser del hombre y se operacionaliza mediante el lenguaje, pues para el autor el lenguaje nos ubica en el mundo. En razón de esto último, trabajar desde una visión hermenéutica es entrar en diálogo con los textos, conversar con el texto. Y esto es lo que hemos hecho en nuestra investigación: adentrarnos en las palabras, dejarnos seducir por ellas para poder navegarlas en su semiosis y comprender así desde dónde se sitúan nuestros sujetos docentes cuando se expresan en torno a los alumnos que poseen alguna discapacidad y estudian en una escuela común.

Los aspectos delineados en atención al trabajo interdisciplinario que presentamos a continuación, han venido funcionando como guías durante el recorrido investigativo, aunque es importante señalar que también han aparecido incertidumbres que ocasionan desvíos, retornos. Esto, claro está, forma parte de los desencuentros que siempre hay en el camino del investigador, pero que al final se integran en la creatividad y autonomía que se persigue.

En cuanto a las herramientas lingüístico-discursivas de análisis que asumimos para investigar, centramos el trabajo en las estrategias lingüístico-retóricas mediante las cuales se concretan las representaciones sociales de los hablantes, y en los tópicos relevantes que se ponen de manifiesto en el recorrido discursivo presente en los textos. La evidencia lingüística puede ser investigada desde los distintos niveles posibles (fonético, sintáctico, semántico, pragmático). En las próximas líneas presentaremos de qué forma asumimos la investigación en el plano de lo lingüístico.

\section{EL ACD: UNA PUESTA EN ESCENA DESDE LA INTERDISCIPLINARIEDAD}

La aplicación que presento a continuación nació de la propuesta de una línea de investigación en ACD que actualmente coordino y dentro de la cual asesoro varios proyectos. Uno de estos proyectos, en el cual participo activamente, se circunscribe al ámbito de lo educativo, particularmente para investigar sobre las actitudes de los educadores, a través del análisis crítico de sus actos de habla más cotidianos, para interpretarlos y develar posibles rasgos discriminatorios subyacentes en sus discursos, cuando se refieren a los niños que, estudiando en una escuela común, presentan alguna discapacidad.

El trabajo que se ha venido desarrollando pretende también constituirse en una contribu- 
ción con el conocimiento de realidades artificiosamente solapadas que se hacen presentes en la discursividad de muchos docentes y que obstaculizan el cambio de visión hacia las personas con discapacidad, quienes tiene todo el derecho de ser integradas a la sociedad, pues solo así es posible ir nutriendo la conciencia social basada en el respeto y valoración por la diversidad humana.

El interés por esta temática surge, en buena medida, por la revisión de algunos planteamientos educativos realizados desde organismos internacionales, donde se destaca que una de las dificultades que obstaculiza el proceso de inclusión de niños y jóvenes con discapacidad en la escuela común se refiere a las creencias que tienen los docentes con respecto a las posibilidades reales de integración educativa de las personas con discapacidad. Tales creencias y actitudes están altamente condicionadas por visiones históricas y culturales.

Partiendo de una revisión teórica de lo histórico, de acuerdo con las investigaciones de Talou (2005) y la valoración que de ellas realiza Rodríguez (2007), la discapacidad ha venido siendo resignificada a través del tiempo. Se plantea un primer modelo, denominado de prescindencia, cuyo origen se sitúa en las sociedades grecorromanas, donde la concepción de la insuficiencia como castigo por el pecado y el derecho social al exterminio de seres enfermizos débiles e inútiles refleja la clara relación entre insuficiencia y exclusión. Desde este modelo, interpretamos que las causas que dan origen a la discapacidad son de orden religioso; en este contexto, las personas con discapacidad se consideran innecesarias por diferentes razones: porque se estima que no contribuyen a resolver problemas de la comunidad, o porque albergan mensajes diabólicos, que son la consecuencia del enojo de los dioses, o que - por lo desgraciadas-, sus vidas no merecen la pena ser vividas. Como consecuencia de estas premisas, la sociedad asume el calificativo de seres anormales para estas personas.

El segundo modelo se puede denominar rehabilitador. Desde su filosofía se considera que las causas que originan la discapacidad no son religiosas, sino clínicas, derivadas en limitacio- nes individuales de las personas por causa de una enfermedad. Las personas con discapacidad ya no son consideradas inútiles o innecesarias, pero siempre en la medida en que sean rehabilitadas. Es por ello que el fin primordial que se persigue desde este modelo es normalizar a las personas con discapacidad.

Un tercer modelo, denominado social, es aquel que considera que las causas que originan la discapacidad no son ni religiosas, ni clínicas, sino que son, en gran medida, sociales. Desde esta filosofía no se intenta negar la condición personal, pero se insiste en que las personas con discapacidad pueden aportar a la sociedad en igual medida que el resto de personas, pero siempre desde la valoración y el respeto por la diferencia. Este modelo se encuentra íntimamente relacionado con la asunción de ciertos valores intrínsecos a los derechos humanos, y aspira a potenciar el respeto por la dignidad humana, la igualdad y la libertad personal, propiciando la inclusión social, y sentándose sobre la base de determinados principios: vida independiente, no discriminación, accesibilidad universal, entre otros. Parte de la premisa de que la discapacidad es en parte una construcción y un modo de opresión social, y el resultado de una sociedad que no considera ni tiene presente a las personas con discapacidad. Así mismo, apunta a la autonomía de la persona con discapacidad para decidir respecto de su propia vida, y para ello se centra en la eliminación de cualquier tipo de barrera, a los fines de brindar una adecuada equiparación de oportunidades.

Desde los espacios pedagógicos, y desde los marcos legislativos, es esta última concepción la que se ha tratado de privilegiar, en la búsqueda por la integración escolar de las personas con alguna discapacidad. Sin embargo, en la discursividad social encontramos todavía la presencia de valoraciones que discriminan a quienes poseen alguna discapacidad por considerar que carecen de potencialidades para integrarse satisfactoriamente en la sociedad.

De allí que el ACD, como perspectiva analítica, se constituye en valiosa guía que permite develar intencionalidades, creencias y prejuicios desde la perspectiva émica de los docentes, re- 
tando la ética del investigador, que se adentra en el complejo mundo del lenguaje como acción para interpretar, desvestido de prefiguraciones y preconceptos, las señales cognitivas, emotivas y conductuales que circundan las actitudes del educador, expresadas a diario en su modo particular de lenguajear. Cabe aquí una cita de Maturana (1995), para quien el lenguaje es uno de los mecanismos humanos más formidables para formar el pensamiento y la conciencia, pues es el estructurador básico de nuestras categorías de pensamiento y, por lo tanto, es un excepcional mecanismo de producción y reproducción simbólica e ideológica que refuerza la discriminación y los prejuicios. Dado que su uso es casi inconsciente, se torna en una urgente necesidad que se visibilice, se vuelva consciente y logremos así modificarlo a través de procesos de reflexión y toma de conciencia.

Continuando con la revisión de las teorías, consideramos ineludible penetrar en la psicología social para nutrir la investigación con algunos planteamientos en torno a la actitud como constructo psicosocial, que hace alusión a una tendencia o predisposición aprendida, más o menos generalizada y de tono afectivo, a responder de un modo bastante persistente y característico, por lo común, positiva o negativamente (a favor o en contra), con referencia a una situación, idea, valor o a una persona o grupo de personas, desde la configuración de sus tres componentes fundamentales (Alemany, 2007; Verdugo, 2003; Rodríguez, 2007).

El componente cognitivo: Se refiere a nuestras ideas, creencias o percepciones sobre un referente actitudinal. Decir "Síndrome de Down" automáticamente sugiere una serie de ideas (retraso mental, ojos rasgados, dócil, cariñoso) que no tienen por qué ser verdaderas, ni necesariamente estar basadas en datos objetivos o en nuestra experiencia directa con estas personas. El componente afectivo: Define el conjunto de emociones asociadas a un pensamiento o idea. En el caso anterior, la imagen mental de un adolescente con esas características puede hacernos sentir agrado, pena, suscitar ansiedad o miedo. El componente conductual: Describe las acciones o tendencias de acción asociadas a los componentes anteriores. Pueden ser de tipo abierto (contacto, evitación, ayuda) o encubierto (rechazo, desprecio, silencio), este último es el más difícil de detectar.

De acuerdo con estos tres últimos autores citados, las actitudes son adaptativas en la medida en que nos ayudan a organizar nuestras ideas sobre las cosas, definiendo elementos comunes que las caracterizan y las agrupan en categorías y los patrones de comportamiento adecuados a cada situación.

En el ámbito educativo, las actitudes de los docentes y compañeros son una de las variables más importantes para la integración de los escolares con necesidades educativas especiales, ya que como seres sociales todos tenemos derechos a obtener oportunidades para poder compartir con nuestros pares; constituyendo, por tanto, el "punto de partida" para el éxito en el proceso integrador (Shea \& Bauer, 1999).

Lo anterior permite comprender el valor sustantivo que tienen los actos del habla de los docentes como una herramienta poderosísima para posibilitar o inhabilitar espacios de participación para los estudiantes con discapacidad en la escuela primaria, pues nos permite develar cómo determinadas prácticas discursivas pueden funcionar ideológicamente para discriminar a miembros de un grupo, favoreciendo determinadas percepciones, interpretaciones y acciones en las prácticas sociales, especialmente en contextos temporales y espaciales tan influyentes como la educación primaria.

Si, además, consideramos que la cognición social compartida, y expresada en los discursos cotidianos, por una alta proporción de los docentes en relación con la discapacidad, está asociada a nociones como sufrimiento, desgracia, castigo y enfermedad; es fácil entender que deseen, ante las demandas integradoras del Sistema Educativo, evadir situaciones profesionales que perciben como fuente de fracaso y frustración laboral, procurando enmascarar sus reales creencias y prejuicios con discursos compasivos y limitadores. Esta carga ideológica, expresada en el discurso de los docentes, tiene, a juicio de van Dijk (2003), 
un propósito implícito y hasta inconsciente de reproducción de creencias y prejuicios discriminatorios que se contextualiza en la escuela como medio esencial para la expansión cultural del sistema social imperante.

Vistas, de manera resumida, la contextualización de la realidad y las consideraciones de orden teórico en las que hemos venido anclando la investigación realizada, enunciamos a continuación la pregunta desde la cual diseñamos el recorrido epistémico a seguir:

¿Cuáles son las valoraciones y creencias que atribuyen los docentes al estudiante con discapacidad que asiste a la escuela común?

En atención a esta pregunta central, surgen los siguientes objetivos:

- Interpretar, en el discurso de los docentes, sus actitudes hacia los estudiantes con discapacidad, a través de los indicadores cognitivo, afectivo y conductual.

- Revelar las estrategias discursivas usadas por los docentes, que evidencian rasgos discriminatorios asociados a creencias, emociones y acciones en torno a la discapacidad.

A la luz de la investigación que hemos venido realizando, considero que los procesos de investigación en las ciencias sociales deben asumirse con criterio comunicativo y dialógico, pues el hombre construye sus relaciones sociales y los conocimientos, sobre la base de la interacción comunicativa. Al respecto, afirma González (2007):

La comunicación es una vía privilegiada para el conocimiento de las configuraciones y procesos de sentido subjetivo que caracterizan a los sujetos individuales $\mathrm{y}$, a través de ellos, conocer la forma en que diferentes condiciones objetivas de la vida social afectan al hombre (p. 9).

En atención a los planteamientos anteriores, se hace necesario precisar el paradigma de investigación asumido aquí, entendiendo que un paradigma es: "un sistema de creencias, principios, valores y premisas que determinan la visión que una determinada comunidad científica tiene de la realidad, el tipo de preguntas y problemas que es legítimo estudiar, así como los métodos y técnicas válidos para las respuestas y soluciones" (Contreras, 1996, p. 110).

Derivada de esta noción, la idea de que una teoría es parte del propio paradigma donde se contextualiza es una realidad cierta, que, además, alude a las consideraciones teórico-metodológicas que definen a una comunidad científica. De esta manera, un paradigma, como sistema de principios o supuestos, hace referencia a la naturaleza de la realidad investigada (lo ontológico), el modelo de interacción investigador/investigado (lo epistemológico) y el modo de obtención del conocimiento sobre la realidad investigada (lo metodológico).

En esta investigación, el paradigma epistémico a seguir es el interpretativo. La justificación viene dada por el carácter sociológico y cultural de la investigación, mediante la cual se interpreta, en espacios comunicativos, la subjetividad de los actores implicados en el contexto en el cual se enmarca la realidad investigada. De esta manera, la subjetividad, como categoría relevante en las ciencias sociales, es una dimensión presente en cualquier fenómeno de naturaleza humana, social y cultural. Vale la pena citar a González (2007, p. 17), quien afirma que "los espacios sociales generan formas de subjetivación que se concretan en las diferentes actividades compartidas por los sujetos y que pasan a ser, con sentidos subjetivos diferenciados, parte de la subjetividad individual de quienes comparten esos espacios".

Las ideas esbozadas en el párrafo anterior me condujeron a transitar por el camino de la hermenéutica, pues con ella logramos el acercamiento que debe existir en el proceso intersubjetivo para adentrarnos en la textualidad y generar interpretaciones. Dar sentido hermenéutico a un texto, es, entonces, penetrar en lo discursivo para lograr la comprensión de lo que en él se dice y de lo que se quiere significar sin necesidad de decirlo. En el caso de esta investigación, hemos entablado una dinámica conversacional con un grupo de sujetos docentes que en muchos trechos de los encuentros dialógicos hacen emerger sus propias subjetividades y las convierten en significados, 
explícitos y/o encubiertos mediante el lenguaje, como objeto de la linguisticidad.

Es importante recalcar que en esta investigación se ponen de manifiesto las cuatro dimensiones fundamentales para un abordaje interpretativo de los hallazgos:

Dimensión ontológica: la naturaleza de la realidad investigada se constituye en la base para asumir la realidad social desde una óptica humanista. Partimos del hecho que los sujetos comparten un contexto sociocultural, razón por la cual resulta fundamental interpretar las creencias y valoraciones de los docentes en torno a la discapacidad, desde la visión de quienes participan de la realidad social involucrada.

Dimensión epistemológica: el vínculo entre el sujeto de investigación y el investigador resulta clave importante para la definición de los hallazgos. De acuerdo con Rusque (1999, p. 103) "las perspectivas cualitativas proponen reunir el objeto y reconstruir el sujeto que concibe el objeto en un proceso constitutivo mutuo". No obstante, el investigador asume que para involucrarse realmente con la realidad social y humana es necesario partir de su naturaleza ontológica.

Dimensión procedimental: en esta dimensión, el investigador indaga para encontrar las estrategias que le posibiliten penetrar la realidad en la búsqueda del conocimiento. Resulta importante, entonces, tomar en cuenta dos acciones indispensables:

a. Establecer la naturaleza de las fuentes de información que resulten más apropiadas para realizar las distintas interpretaciones.

b. Valerse de perspectivas sistemáticas que permitan la entrada a la realidad en concordancia con la visión del investigador en cuanto a la dimensión ontológica de lo estudiado.

Dimensión técnica: tiene que ver con las técnicas y estrategias que hacen posible la obtención de la información a partir de la evidencia. Los distintos actores sociales son informantes que han sido seleccionados tomando en cuenta las sugerencias metodológicas que definen a los informantes clave.

En cuanto a este último aspecto, en la investigación nos hemos valido de un instrumento para provocar la expresión del otro como sujeto. Consideramos que, desde una perspectiva interpretativa, todo instrumento debe abordarse como una fuente de información, aislada de sistemas de categorías establecidas a priori, para otorgar luego significados. En razón de esto, tal como lo afirma González (2007, p. 30), "el instrumento es una herramienta interactiva, no una vía objetiva generadora de resultados capaces de reflejar directamente la naturaleza de lo estudiado independientemente del investigador". Por ello, resulta muy valioso, al aplicar un instrumento, facilitar las expresiones del otro, de los sentidos subjetivos, privilegiar la expresión de los otros como proceso, para así estimular la producción de tejidos de informaciones y no de respuestas precisas.

En este trabajo nos hemos apoyado en la dinámica conversacional, pero hacemos la salvedad de que no hemos seguido pautas estandarizadas para la construcción de un guión que nos sirviera de apoyo. Consideramos que para la producción de sentido no es la forma como se construye el instrumento lo esencial.

En esta investigación realizamos una conversación entre el investigador y todos los participantes de manera simultánea. Sin embargo, en la relación investigador e informante tratamos de que la interacción se diera lo más organizada posible. Cada participante al tomar el turno de habla lo hacía de manera reflexiva y colaboraba a través de las distintas posiciones personales que asumía en torno al tema central de la investigación.

Para instaurar cada conversación se partía de comentarios, preguntas, reflexiones que consideramos podían abrir de manera natural el canal de interacción. De esta manera fue muy importante el sentido de creatividad y la iniciativa durante este proceso.

Cabe destacar que en nuestra investigación cada expresión de los participantes fue interpretada de manera diferenciada. Aquí, el contexto interpretativo no estuvo signado por el instrumento, sino por los sujetos participantes a partir de todas las complejidades de sus expresiones.

La información obtenida a través de las diná-

\section{Cumbres}


micas conversacionales sostenidas con las tres docentes, se analizó con la intervención del análisis crítico del discurso (ACD), para interpretar en la discursividad de un grupo de docentes de educación primaria, en atención a las tres dimensiones actitudinales tomadas de los preceptos de la psicología social (cognitiva, emocional y conductual), las creencias y valoraciones en torno a los niños con discapacidad. Para ello seleccionamos y analizamos los tópicos más resaltantes en cada dimensión explorada. En este sentido los tópicos estuvieron representados por macroproposiciones que expresan opiniones y, de manera subyacente, estereotipos y prejuicios. Al respecto, van Dijk (1998), indica que no cabe duda que los tópicos son posiblemente las estructuras del discurso que más efecto tienen en la construcción y en el procesamiento de los modelos mentales (representaciones sobre la discapacidad). Así, las representaciones son el resultado de las estrategias cognitivas (reactivación de la memoria, conocimiento general, opiniones, creencias) que utilizamos de forma dinámica, tentativa y recursiva (van Dijk, 1997).

En el análisis del significado discursivo, atendimos también a la construcción de las representaciones tomando en cuenta las actitudes de los docentes, mediante las cuales manifiestan sus puntos de vista y expresan sus posiciones utilizando algunas estrategias discursivas. Seguimos la clasificación que propone Wodak (2000), y organizamos la información tomando en cuenta lo que emergió de los discursos: a) las estrategias de nominación que utilizan los docentes para referirse a los niños con discapacidad, en estas se incluyen categorías como la metáfora y la metonimia; b) las estrategias predicativas mediante las cuales realizan atribuciones estereotipadas y valorativas de rasgos positivos y negativos ; c) las estrategias de intensificación y mitigación.

A manera de ejemplo, en la tabla 1 aparecen las dimensiones actitudinales exploradas, así como los tópicos más significativos y la evidencia lingüística que da representación a los mismos.

$\mathrm{Al}$ realizar la interpretación de los textos, desde la profundidad del ACD, podemos aportar algunas consideraciones importantes.

Tabla 1. Dimensiones actitudinales, expresión y significados de los tópicos relevantes a través de la interpretación del discurso de los docentes

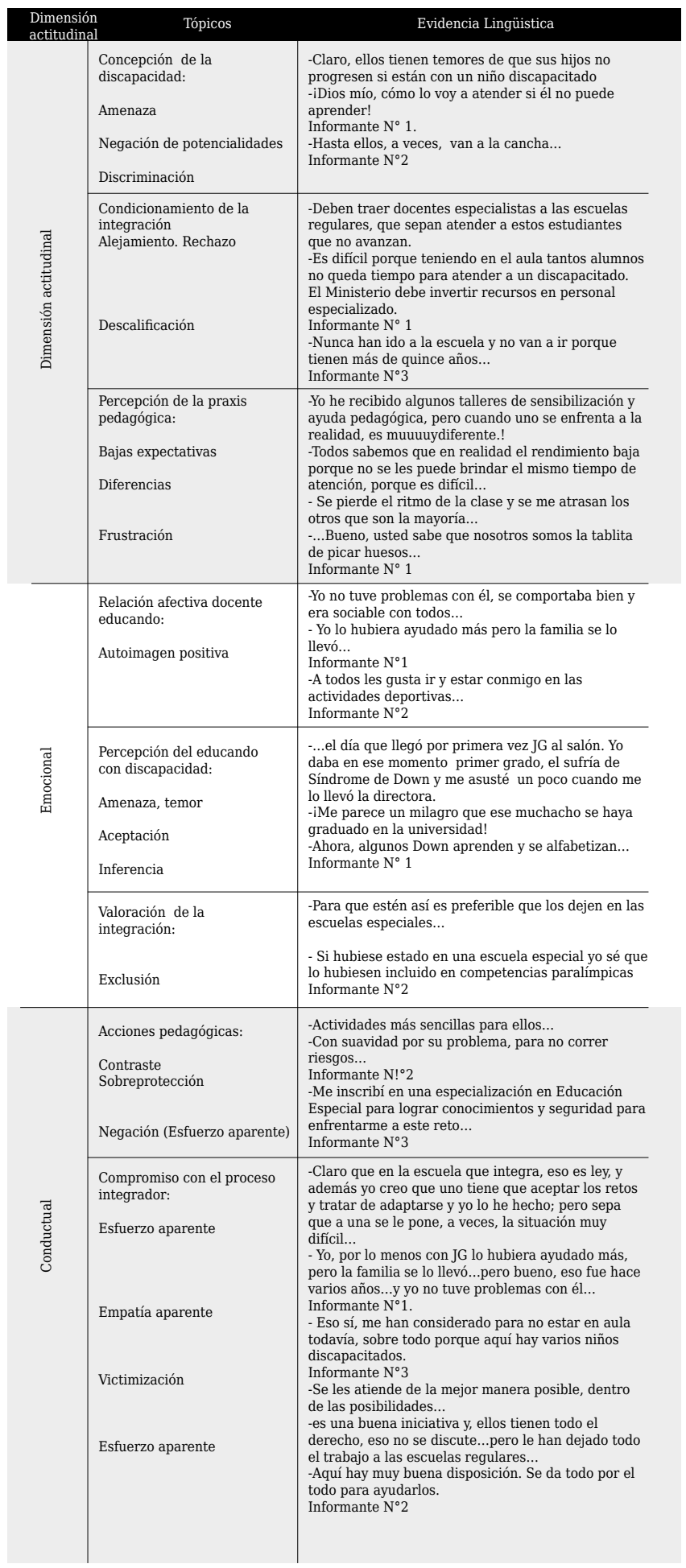


No encontramos, hasta ahora, en los discursos de los docentes, diferencias significativas en las actitudes que tienen con respecto a los educandos con discapacidad y su proceso de integración escolar. Lo que sí resulta evidente es el uso de variadas estrategias discursivas en sus actos de habla, como expresiones de intencionalidades comunes, asociadas a creencias discriminatorias hacia los estudiantes con discapacidad y la falta de compromiso con su proceso de integración en la escuela común. Esto permite aseverar que estos rasgos característicos de los docentes tienen su origen en la cognición social.

En cuanto a las unidades de análisis utilizadas debo declarar el valor recursivo del ACD para interpretar los enunciados y develar formas de cognición social que se solapan en expresiones, aparentemente ligeras e intrascendentes. En este sentido, la construcción del cuadro relacional entre las dimensiones actitudinales, los tópicos o temas emergentes y la representación linguística, como evidencia de las estrategias que utilizaron las docentes, me sitúan en la aproximación de un panorama discursivo complejamente entramado, en su forma y contenido, pleno de evidencias que revelan actitudes discriminatorias

Se hace notorio, en la diversidad de expresiones léxicas utilizadas por las docentes, los rasgos discursivos asociados a un modelo de pensamiento que valida y justifica la discriminación de las personas con discapacidad. Expresiones como: iQué lástima!, iNo puede aprender!, iNunca atiende!, iNo puede!, denotan compasión, descalificación y minusvalía, evidenciando que el paradigma rehabilitatorio, que concibe a la persona como enferma y víctima de su desgracia personal, se mantiene latente en la conciencia de estas docentes.

En cuanto a las estrategias retóricas identificadas en los discursos analizados, se reafirma el uso de expresiones que revelan posturas homogeneizadoras ante el hecho educativo, y por ende segregadoras de los estudiantes que resulten diferentes a los patrones mentales establecidos. También resulta interesante apreciar los intentos de atenuación, con rebusques discursivos que pretenden aligerar la fuerza ilocutiva e intencio- nalidad perlocutiva de las palabras comprometidas.

La evidencia lingüística revela también el temor de las docentes para expresar abiertamente sus creencias, emociones y formas de accionar frente al proceso de integración educativa de las personas con discapacidad. Este es un indicativo que dificulta el proceso de cambio en sus creencias y modelos de pensamiento; ya que sólo develando realidades, por contrarias que estas sean al paradigma de inclusión social, lograremos iniciar un real proceso transformador. De lo contrario, se mantendrán enmascaradas en discursos y acciones ambiguas y contradictorias oscureciendo aún más el panorama integrador.

Por otra parte, teniendo en cuenta la estrecha relación, evidenciada en este estudio, entre la ideología y el discurso, como forma de cognición social que influye de forma determinante en lo que decimos y cómo lo decimos, se hace imperativo pensar en la reversibilidad de una realidad limitadora y segregacionista que alcanza al educador como agente sensible para la perpetuación o cambio ideológico. Si, además, consideramos que las ideologías son aprendidas y, por tanto, reaprendidas, se hace esperanzadora la idea de trabajar la reflexión discursiva, escrita y oral, como estrategia para crear nuevos modelos mentales de representaciones sociales e ideologías abiertas a la valoración del proceso inclusivo de las personas con discapacidad.

Para alcanzar esta realidad, aún utópica, para una alta proporción de los actores educativos, además del respaldo jurídico y legal, es muy importante el aprendizaje y reaprendizaje continuo de los docentes, a través de la revisión y reflexión discursiva, como estrategia para enfrentar y vencer las barreras actitudinales. Sólo así lograremos que en el mediano y largo plazo se formen nuevas generaciones de maestros y estudiantes y se establezcan nuevos paradigmas de valoración y relación humana.

Finalmente, debo manifestar, como hallazgo valioso en este encuentro con el ACD, un particular proceso de reflexión y valoración de mis cogniciones y prefiguraciones, que me exigen mayor prudencia discursiva y sensibilidad ante los actos 
del habla de quienes comparten mi contexto relacional.

\section{REFERENCIAS BIBLIOGRÁFICAS}

Alemany, I. (2007). La actitud de los docentes frente a la integración. Argentina: Noveduc.

Aramayo, M. (2004). La Discapacidad. Construcción de un modelo teórico venezolano. Caracas: Fondo Editorial de la Facultad de Medicina.

Berardi, L. (2003). Análisis Crítico del Discurso: Perspectivas latinoamericanas. Santiago: Frasis.

Bolívar, A. (2004). Discurso e interacción en el texto escrito. Caracas: Consejo de Desarrollo Científico y Humanístico.

Bolívar, A. (2007). Análisis del Discurso. Caracas: Los libros de El Nacional.

Contreras, M. (1996). La investigación en el aula en el marco de la investigación cualitativa en educación, una reflexión acerca de sus retos y posibilidades. Revista Educación (San José), 20(1), 109-125.

Fairclough, N. (1992). Discourse and social change. London: Longman.

Fowler, R., Hodge, B., Kress, G., \& Trew, T. (1979). Language and control. London: Routledge y Kegan Paul.

Gadamer, H. (1992). Verdad y método. Salamanca: Edit. Sígueme.

González, F. (2007). Investigación cualitativa y subjetividad: Los procesos de construcción de la información. México: Mc Graw Hill.

Iñiguez, L. (2003). Análisis del Discurso: Manual para las Ciencias Sociales. Barcelona: UOC.
Kress, G., \& Hodge, R. (1979). Language as ideology. Londres: Routledge.

Kress, G., \& Van Leeuwen. (1990). Reading images. Geelong: Deakin University Press.

Martín, L., \& Whittaker, R. (1998). Poder-Decir o el poder de los discursos. Madrid: Arrecife.

Maturana, H. (1995). Emociones y lenguaje en educación y política. Chile: Ediciones Pedagógicas Chilenas.

Molero de Cabeza, L. (2003). El enfoque semántico-pragmático en el análisis del discurso. Visión teórica actual. Lingua Americana, (12), $5-28$

Naciones Unidas. (2007). Convención de derechos de personas con discapacidad. Recuperado de http://www.un.org/spanish/disabilities/documents/gid/conventionfaq.pdf

Núñez, N. (2003). Entre usos lingüísticos y actos de habla. Caracas: Comisión de Estudios de Postgrado.

Rodríguez, A. (2007). Hacia la inclusión en la escuela común de niños, niñas y adolescentes con discapacidad (Trabajo de ascenso no publicado). Universidad Pedagógica Experimental Libertador. Instituto Pedagógico "Luis Beltrán Prieto Figueroa”, Barquisimeto, Venezuela.

Rodríguez, A. (1991). Psicología Social. México: Trillas.

Rusque, A. (1999). De la diversidad a la unidad en la investigación cualitativa. Caracas: Vadel Hermanos Editores C A.

Shea, A., \& Bauer, A. (1999). Educación especial desde el enfoque ecológico. México: Mac Graw Hill.

Soriano, M. (2005). La programación neurolin- 
güística como estrategia comunicacional del docente en su rol de orientador para ejercer un liderazgo transformacional (Tesis doctoral). Universidad Pedagógica Experimental Libertador: Instituto pedagógico de Barquisimeto.

Talou, C. (2005). ¿Pueden ir a la escuela contigo?. Buenos Aires: Novedades Educativas.

UNICEF (2001). Hacia el desarrollo de escuelas inclusivas. En HINENI, UNESCO y UNICEF. Ciclo de debates: Inclusión de niños con discapacidad en la escuela regular. Santiago, Chile.

van Dijk, T. (1994). Principios del análisis crítico del discurso. Discurso y sociedad, 4(2), 193223.

van Dijk, T. (1997). El discurso como estructura y proceso. Barcelona: Gedisa.

van Dijk, T. (1998). Ideología: Una aproximación multidisciplinaria. Barcelona: Gedisa.

van Dijk, T. (2000). El discurso como interacción en la sociedad. En T. van Dijk (Ed.), El discurso como interacción social (pp. 19-66). Barcelona: Gedisa.

van Dijk, T. (2003). Prólogo. En L. Iñiguez (Ed.), Análisis del Discurso: Manual para las Ciencias Sociales (pp. 11-16). Barcelona: UOC.

van Dijk, T. (2003). Ideología y Discurso: Una Introducción Multidisciplinaria. Barcelona: Ariel.

Verdugo, J. (2003). Apreciamos las diferencias. Salamanca: Sidal.

Wheterell, M. (2001). Debates in Discourse research: Discourse Theory and Practice. London: Sage.

Wittgenstein, L. (1958). Philosophical investiga- tions. Oxford: Basil Blackwell.

Wodak, R. (2000). ¿La sociolingüística necesita una teoría social? Nuevas perspectivas en el análisis crítico del discurso. Discurso y sociedad, 3(2), 123-147.

Wodak, R. (2003). De qué trata el análisis crítico del discurso. Resumen de su historia, sus conceptos fundamentales y sus desarrollos. En R. Wodak, Métodos de análisis crítico del discurso (pp. 17-34). Barcelona: Gedisa. 